\title{
1. Introduction: following the researchers into the field
}

\author{
David S. A. Guttormsen, Jakob Lauring and \\ Malcolm Chapman
}

The Field Guide to Intercultural Research, published by the internationally renowned publisher, Edward Elgar Publishing, invites readers to follow 48 authors into their research fields in nearly 20 different countries across the African, Asian, Australian, European and Middle Eastern regions. In 26 chapters, in addition to both a preface and an afterword, the authors who are representing more than 20 nationalities, narrate their experiences with solving intercultural challenges encountered during fieldwork - predominantly overseas but also in the home country.

Intercultural challenges can engender a 'make-or-break' juncture in terms of the success or failure of the fieldwork and, thus, an entire research project. Negative impact arising from such challenges often inhibits a researcher's ability to access the required physical research sites and information, to develop and find answers to particular research questions or practitioner problems, as well as to secure the participation of the needed research subjects and communities/organizations to complete the planned study and - importantly - to comprehend and present the actual lived experiences and meanings construction of those we have set out to investigate in an ethical, credible and authentic manner (Ardener, 1989a, 1989b; Chapman, Gajewska-De Mattos \& Antoniou, 2004; Delios, 2017; Doh, 2017; Fjellström \& Guttormsen, 2016; Lauring, 2007; Lauring \& Selmer, 2009; Malinowski, 1967; Moore, 2011; Primecz, Romani \& Sackmann, 2011; Wacquant, 2004; Welch et al., 2001; Welch \& Piekkari, 2006; Zhang \& Guttormsen, 2016).

Collectively, the chapters engage with an array of intercultural challenges faced by researchers in the field - encompassing practical aspects of fieldwork, the local, organizational/professional and national cultures surrounding the researcher and the researched in the field, in addition to theoretical, methodological, research philosophical and linguistic concerns. Several of the chapters depict cultural challenges relating to the interpersonal relationships that formed between the researcher and those being researched. Additionally, perhaps a surprise to many, the Field Guide also features intercultural chal- 
lenges when it comes to quantitative survey projects (e.g., Harzing, Reiche \& Pudelko, 2013), albeit that fieldwork is predominantly associated with qualitative research. In fact, quantitative researchers too at times find themselves at the grace of the big wonders of the living laboratories - and the lived experiences they harbour - when sourcing respondents in the field.

In addition to penning their experiences, the authors convey their 'lessons learned' and offer 'practical tips', which can be helpful to both the budding doctoral or early-career field researcher as well as the more seasoned colleague who might be revisiting field research after spending some time away from this avenue of data collection. The relevance of said practical recommendations can extend beyond the academe and into the professional world of work management consultancy, market and consumer research, in addition to an organization's in-house (action-based) research projects.

By 'intercultural' we mean interaction between individuals from different cultures across country borders or within a country (Frenkel, Lyan \& Drori, 2015), and encounters that transpire between individuals and socio-historically embedded multicultural organizations and institutions both abroad and at home (Holmes, 2015). By 'field', we mean any physical settings or contexts for collecting data from research subjects or organizations - and where learning exchanges occur, in their natural environments away from our own offices, classrooms and laboratories. These physical sites can, of course, constitute a 'field' if the study is about people and phenomena relating to these locales. Key aspects encompass achieving an insider's view and where the researcher immerses themselves in said natural context (Pole \& Hillyard, 2016). And so is how we produce knowledge about those we study and how we choose them and the exploration of Otherness (Wacquant, 2004). For this particular Field Guide we have focused on fields limited to business activities and work organizations - beyond corporate settings and scholars outside the broader business and management discipline. Indeed, scholars from a host of disciplines study the world of work and professionals, and obviously work is carried out in a range of sectors beyond the private sector - although sometimes the business school academe appears to forget this.

Why is it important to study intercultural challenges during fieldwork? For most part, fieldwork is an underused data-collection approach in business and management studies (Bate, 1997; d'Iribarne, 1997; Linstead, 1997; Moore, 2011; Rosen, 1991), although one of the most employed methods in the wider social sciences - for example, making social anthropology a distinct discipline in this landscape for more than a century (Keesing \& Strathern, 1998). It probably relates to the fall from grace of the hegemonic position of the scientific method that manifested itself in a North American-dominated intellectual tradition within the post-war phenomenon of business and management schools (Adler, 1983a, 1983b; Boyacigiller \& Adler, 1991; Chapman, 1997; Doktor, 
Tung \& Von Glinow, 1991; Hofstede, 1993; Peng, 2004; Simon, 1991, cited in Lynn, 2006, p. 40).

As the editors of the Field Guide, we are excited about creating a community of field researchers as well as contributing to the wider methodological and research philosophical debates revolving around contemporaneous field research challenges - in particular, the role of culture - in various sociocultural contexts. We are also excited about presenting a compilation of chapters on this topic; just as the fieldwork experiences of the authors featured in this Field Guide signal significant milestones in their academic careers, field research also represents a major chapter in our own scholarly pursuits in the business of producing, comprehending and presenting (new) knowledge. For us, the editors, as with most others field researchers, to conduct field research reflects our professional identities, epistemological and ontological 'postures' and, indeed, is a highly appreciated joy in life - to interact with, and understand, people, corporate life and organizations within their natural settings and local cultures - and to immerse ourselves with all the messy and complex contextual specificities that come with it. It makes fieldwork exciting and rewarding - as well as challenging and stressful - when we endeavour to discover original or nuanced knowledge about the intricacies of human nature, social life and the enmeshed nature of actual lived experiences as well as the interplay with, and social constructions of, the physical/material world and the world of ideas and meanings. After all, are not the social sciences essentially about identifying structures in chaos?

In terms of the trajectory of an academic career, fieldwork often forms and defines your future research interests that you (re)discover in the field - many of them perhaps not addressed in extant academic literature. Hence, the traditional 'gap searching' in the literature for justifications of a research project might quickly become a remote concept. Furthermore, researchers often develop from this foundation their research into philosophical identities and where they stand in terms of the nature of the research process - granting the primacy to field research data or existing theory (see Hammersley \& Atkinson, 2007), the latter being the more conventional approach and assumed to constitute the 'science proper' approach in mainstream business and management studies, which, arguably, is monopolized by positivism (Chapman, 1997; Guttormsen, 2015; Guttormsen \& Lauring, 2018).

Carrying out fieldwork often becomes a momentous experience in the life of an academic. As a personal experience, it is often remembered as a major undertaking as it often involves staying abroad/at a different location for several months - and even years - and requires you to be immersed in a new and unfamiliar environment but which you nevertheless find enticing. Many a researcher would associate fieldwork with a high financial cost, often self-financed, due to their passion to investigate a world they want to under- 
stand - a different world, the Otherness - and perhaps even contributing to this world with their research outputs. As a person, the researcher develops local knowledge, builds professional networks relevant for future projects and positions themselves to pass on 'real' knowledge in their classrooms, which is often highly appreciated by students as the supreme form of knowledge. Friendships are often established in the field, thus being integral to a researcher's personal growth and social life. Nevertheless, this forces the field researcher to constantly reflexively consider the concepts of subjectivity and objectivity - in addition to their integral role in the knowledge production (Bourdieu, 2004; Wacquant \& Bourdieu, 1992). This is a good thing. It also emphasizes the under-focused process of exiting the field in an advantageous fashion (Michailova et al., 2014) and the various types of relationship that the field researcher becomes embroiled in - especially beyond interpersonal relationships with research subjects due to having been a focus in methodological and ethical debates.

The lead editor, David S. A. Guttormsen, got hooked on fieldwork as a postgraduate research student at Leeds University Business School, United Kingdom (in fact, under the supervision of the co-editor Malcolm Chapman). After carrying out a five-month ethnographic study of Scandinavian expatriates in Hong Kong, SAR (Guttormsen, 2010), David continued to nurture his keen interest in field research after experiencing the wealth of knowledge he could acquire from people holding jobs that interested him both personally and professionally. This was a result of spending hundreds of hours interviewing and observing them as opposed to only receiving answers to a fixed set of survey questions - from people he had never met and/or knew anything about. The above-mentioned MPhil in International Business thesis led to publishing on the expatriate failure concept, where he was able to contest the credibility of its four-decade-long definition by simply asking actual expatriates what 'failure' meant to them - and not to simply assume that the textbook definition had universal applicability, which consequently would have led him to merely count the number of failures based on an invalid and non-credible parameter (see Guttormsen, Francesco \& Chapman, 2018). He has stuck with this social constructionist paradigm since then (Crotty, 2003). These paths also permeated in David's doctoral research project (in politics and international studies) at the University of Warwick when conducting field research on China-policy research experts working in American think tanks (Guttormsen, 2014), under the supervision of Stuart Croft. To date, David has interviewed as part of fieldwork nearly 400 informants in nine countries, and his early training with fieldwork positioned him well to be welcomed in conducting an in-depth, longitudinal qualitative study of one of Scandinavia's leading multinational enterprises regarding their internal global mobility, expatriation, and talent management programmes and practices around the world. 
The co-editor, Jakob Lauring, who rose to a full professorship within only five years at the Department of Management at Aarhus University, Denmark, publishes predominantly quantitative survey-based research (e.g., Jonasson, Lauring \& Guttormsen, 2018; Lauring, Guttormsen \& McNulty, 2019; Lauring \& Jonasson, 2018; Stoermer, Lauring \& Selmer, 2020), although he was initially trained in social anthropology and sociology. His early work centred on ethnographic research and Jakob has continued utilizing this methodology, which especially profited his ability to identify relationships hitherto not identified in extant research (Jonsen et al., 2013; Klitmøller \& Lauring, 2013; Klitmøller, Lauring \& Bjerregaard, 2015; Lauring, 2008; Lauring \& Guttormsen, 2010; Lauring \& Klitmøller, 2015; Lauring \& Selmer, 2009, 2010).

The other co-editor, Dr Malcolm Chapman, worked formerly at Leeds University Business School, United Kingdom, prior to his retirement. Being a trained social anthropologist, with a DPhil in Social Anthropology from the University of Oxford under the supervision of world-renowned linguistic anthropologist, Edwin Ardener (1989a, 1989b), ethnographic fieldwork was and remains the very representation of Malcolm's intellectual faculties since embarking on his university studies, and signals the very DNA of his holistic universe of research. Indeed, his ethnographic fieldwork also became the vehicle for becoming fluent in French - an enterprise and integral opportunity of longitudinal fieldwork that is often not talked about - for example, between a $\mathrm{PhD}$ researcher and the supervisor - in terms of acquiring new language skills that may open up otherwise closed research opportunities in the future and a competitive edge on the job market. After moving to the business school academe, he conducted comprehensive longitudinal ethnographic field studies, including a study of ten international companies in the pharmaceutical industry regarding internationalization (Buckley \& Chapman, 1997), after having published several of his ethnographies: on the Celts (Chapman, 1992); on the Gaelic language (1978); in addition to his unpublished DPhil thesis on the Breton village (Chapman, 1986).

We all rejoice around our aspiration to see more field research integral to scientific knowledge production within the broader business and management research field - and to partake in intriguing methodological debates surrounding fieldwork and the intercultural opportunities and challenges that come with it. We hope that the Field Guide to Intercultural Research can serve the purpose of enticing, and provoking, exactly that. Undoubtedly, the boundary of what can be investigated in this world is exceptionally wider than the boundary of the knowledge that is already known in our established bodies of literature. Hence, we are excited to see what new knowledge, and new understandings, will surface from fieldwork in the years to come and that will subsequently 
challenge our various ivory towers - the emic, context-specific worlds, which practitioners often find the most exciting.

Part I of the book comprises nine chapters with a practical focus, providing general advice and methodological learning points for researchers interested in doing intercultural fieldwork research in an international context. In Chapter 2, W. Travis Selmier II and Aloysius Newenham-Kahindi describe the process of using grounded theory in international field studies. They especially focus on the complexity of doing intercultural social science research. This analysis of the use of grounded theory is illustrated through an account of their data-collection endeavour in a mining company in an African context. Chapter 3 by Anne-Wil Harzing, B. Sebastian Reiche and Markus Pudelko deals with intercultural survey research with a special focus on determining the study population and data access, survey development, survey and data-collection process, data analysis and publication of results. This is illustrated by examples from their own research. William S. Harvey is the author of the Chapter 4. He focuses on how to best interview global elites, such as senior managers in international companies. Throughout this chapter, Harvey argues that the community of field researchers needs guidance, training and reflection on the practices of interviewing elites, as this theme will be of growing importance in the future. In Chapter 5, Indigo Holcombe-James and Ellie Rennie reflect on their experience with survey-based research in remote indigenous communities and provide advice based on their own failed attempts to navigate the data-collection process. Thereafter, the authors discuss the difficulties in using quantitative techniques when applied to indigenous populations. Gunhild Odden uses Chapter 6 to address her experiences with fieldwork among migrant entrepreneurs in Spain. It more precisely shows how the combination of interviews and observation may provide a particularly rich material, but also how structural factors, such as age, nationality, social background and gender, may influence the research process and, consequently, also the findings. Following this, in Chapter 7, Ritam Garg and Petra Poljsak-Rosinski discuss the need for researchers to develop their intercultural sensitivity to deal with different cultural environments. Here, the two authors describe the challenges that intercultural interviewing pose and outline methods for intercultural training that would enable researchers to identify and better deal with such challenges. In Chapter 8, Mai Skjøtt Linneberg and Steffen Korsgaard offer a thorough yet practical introduction to the vocabulary and craft of coding with a specific focus on the intercultural aspects of fieldwork related to coding. They synthesize their experience in coding qualitative material and in how to increase awareness of the intercultural aspects of coding. Chapter 9 is a practical guide to collecting multi-method qualitative data. Here, Jakob Lauring and Charlotte Jonasson focus on how to engage with the iterative research process when doing intercultural fieldwork. This involves generating field-relevant 
research questions, collecting the data, logging the data, analysing the data, writing it up, and then returning to reconsider the research questions. Finally, in Chapter 10, Marta Jackowska describes an entirely new way of doing intercultural fieldwork using digital means. Accordingly, the chapter focuses on the transcription and coding tools that can help in managing large amounts of qualitative data. Moreover, it gives an overview of how epistemic network analysis, one of the techniques of quantitative ethnography, can assist qualitative researchers in the analysis of the fieldwork data.

Part II of the book consists of nine chapters with a theoretical perspective on how to perform intercultural fieldwork. Here, central theoretical themes and debates are outlined and discussed by the authors. The opening chapter is Chapter 11 by Bruce W. Stening. This author provides important insights and lessons learned from being an intercultural researcher. The aim of the chapter is to enable fieldworkers to make meaningful and impactful contributions through their research. After this, Mette Zølner, in Chapter 12, presents a critical reflection on her recent empirical work focusing on the image that the field projected on her as a researcher. The main argument is that the status of foreignness can constitute a valuable asset together with local insights and relations. In Chapter 13, Christopher Richardson explores potential fieldwork challenges that face intercultural researchers investigating the role of religion in organizations. It is argued that, unlike certain aspects of culture, religion is often seen as something of a delicate nature. While relatively little direction to researchers undertaking fieldwork in this area has been offered, it can still pose a unique challenge. Badri Zolfaghari takes a different approach in Chapter 14. Here, he draws on personal experience in conducting mixed-method comparative field studies. He shows that the concept and conceptualization of culture can vary significantly across national cultures. Providing a theoretical foundation for operationalizing culture, this author encourages cross-cultural field researchers to capture the nuances of cultural similarities and differences pertaining to the concepts and constructs they wish to examine. Similarly, in Chapter 15, a group of researchers comprising David S. A. Guttormsen, Petra Poljsak-Rosinski, Htwe Htwe Thein, Trifon Pavkov, Katarina Brkovic and Michael Gillan argue that the culture of the academic disciplines they engage with may lead to intercultural challenges for interdisciplinary researchers conducting fieldwork. From the outset the authors analyse how and why the mentioned challenges may hamper the prospect of a successful field study. In Chapter 16, Masumi Owa provides recommendations on conducting field work in the international development sector. A special emphasis is on how social identity elucidates the different cultures in disparate groups and organizations as well as the relationships among them. Moreover, the chapter discusses the importance of being aware of the multiple identities in order to understand the complexity of social background and challenges faced by 
the interviewees. Also focusing on identity issues, Annelise Ly and Ingrid Onarheim Spjeldnæs in Chapter 17 address the researcher's positioning while conducting fieldwork in foreign contexts. It is argued that accepting one's own subjectivity is particularly important when collecting these types of data, but that identity attributes can be voluntarily downplayed or, on the contrary, highlighted depending on the needs of the researcher.

A similar theme is taken up in Chapter 18 by Charlotte Jonasson, Jakob Lauring and David S. A. Guttormsen. In this chapter, the connection between researcher race and negotiation of his or her role in the field is discussed. The three authors propose that more attention to race is needed because physical first impressions can have important consequences for gaining access to and for conducting fieldwork. In the last chapter of Part II, Christoph Barmeyer and Eric Davoine in Chapter 19 show how a binational researcher team can improve the quality of interactions with the actors of binational organizations. Subsequently, the two authors discuss the intercultural challenges of binational and bilingual research tandems.

Part III of the book provides guidelines and advice on how to do fieldwork in specific local settings, such as Zimbabwe, Nigeria, China, Thailand, Vietnam, the Philippines, India, Lebanon, Jordan, Syria, Qatar, Romania and Russia. Initiating Part III, Nomusa Benita Mazonde argues in Chapter 20 that Western research approaches may be culturally unsuitable within African contexts. This necessitates cultural adaptations in the way to conduct fieldwork. Therefore, the author engages in the dialogue on studying 'the Other' in qualitative inquiry. Chapter 21 by Adebukola E. Oyewunmi, Stephen I. Ukenna and Ebes Esho also tackles the African fieldwork context. The authors argue that the African continent's multicultural fragmentation is duplicated in every member nation. This leads to challenges for intercultural researchers. Specifically, the issues of power distance, ethical dilemma and illiteracy that characterize the setting indicate that intercultural researchers require a cocktail of theoretical and pragmatic research competencies to navigate the realities of conducting research in this context. In Chapter 22, Anna Shostya, Moshe Banai and Joseph C. Morreale describe and analyse challenges encountered while conducting field studies in China. The focus is directed particularly towards political influence and control of the Communist Party, the fast pace of economic and social changes and the characteristics of Chinese culture and society. Attending instead to the Middle Eastern context, Hana Abdo, Amélie Artis and Anne Bartel-Radic in Chapter 23 explain how the Lebanese culture affects qualitative interviewing. Important obstacles identified are confessionalism and nepotism. On the other hand, strong personal networks and relationships are more than helpful in opening doors for qualitative interviews. Chapter 24 by Maranda Ridgway and Fiona Robson similarly provides a reflexive account of the challenges of conducting qualitative fieldwork as an expatriate woman 
in the Middle East. The intersection of gender and nationality is drawn upon to highlight how cultural differences can both inhibit and enable field research in the Middle Eastern region. Also dealing with the Middle East, Sarina Theys in Chapter 25 describes intercultural challenges experienced before and during the fieldwork in Qatar. The challenges discussed relate specifically to field access, local accommodation, interview gatekeepers and awkward moments during interviews. In Chapter 26, Thi My Hanh Huynh and Anne Bartel-Radic draw on their experience of qualitative interviewing in Vietnam. Based on this they present lessons learned and practical tips. And finally, Astrid Kainzbauer and Brian Hunt, in Chapter 27, share their research experiences in Thai organizations, describing three data-gathering research methods - questionnaires, focus groups and face-to-face interviews. They argue for the importance of cultural awareness and biases that may occur when researchers enter the field with a 'Western' mindset.

After the final part of the book, Fiona Moore provides an afterword. Bon voyage!

\section{REFERENCES}

Adler, N. (1983a). A typology of management studies involving culture. Journal of International Business Studies, 2(2), 29-47.

Adler, N. (1983b). Cross-cultural management research: the ostrich and the trend. Academy of Management Review, 9(2), 226-32.

Ardener, E. (1989a). Social anthropology and population. In M. Chapman (Ed.), Edwin Ardener: the voice of prophecy and other essays (pp. 108-26). Oxford: Blackwell.

Ardener, E. (1989b). Language, ethnicity and population. In M. Chapman (Ed.), Edwin Ardener: the voice of prophecy and other essays (pp. 65-71). Oxford: Blackwell.

Bate, S. P. (1997). Whatever happened to organizational anthropology? A review of the field of organizational anthropology and anthropological studies. Human Relations, 50(9), 1147-75.

Bourdieu, P. (2004). Science of science and reflexivity. Chicago, IL: University of Chicago Press.

Boyacigiller, N. A., \& Adler, N. J. (1991). The parochial dinosaur: organizational science in a global context. Academy of Management Review, 16(2), 262-90.

Buckley, P. J., \& Chapman, M. (1997). A longitudinal study of the internationalisation process in a small sample of pharmaceutical and scientific instrument companies. Journal of Marketing Management, 13(1-3), 43-5.

Chapman, M. K. (1978). The Gaelic vision in Scottish culture. Montreal: McGill-Queen's University Press.

Chapman, M. K. (1986). Breton village. Unpublished DPhil thesis, University of Oxford.

Chapman, M. K. (1992). The Celts: the construction of a myth. New York: St. Martin's Press/Basingstoke, UK: Palgrave Macmillan.

Chapman, M. K. (1997). Social anthropology, business studies, and cultural issues. International Studies of Management \& Organization, 26(4), 3-29. 
Chapman, M., Gajewska-De Mattos, H., \& Antoniou, C. (2004). The ethnographic international business researcher: misfit or trailblazer? In R. Marschan-Piekkari \& C. Welch (Eds.), Handbook of qualitative research in international business (pp. 287-305). Cheltenham, UK and Northampton, MA, USA: Edward Elgar Publishing.

Crotty, M. (2003). The foundations of social research: meaning and perspective in the research process. London: SAGE.

Delios, A. (2017). The death and rebirth (?) of international business research. Journal of Management Studies, 54, 391-7.

d'Iribarne, P. (1997). The usefulness of an ethnographic approach to the international comparison of organizations. International Studies of Management \& Organization, 26(4), 30-47.

Doh, J. P. (2015). From the editor: why we need phenomenon-based research in international business. Journal of World Business, 50(4), 609-11.

Doktor, T., Tung, R., \& M. von Glinow, A. (1991). Future directions for management theory development. Academy of Management Review, 16(2), 362-5.

Fjellström, D., \& Guttormsen, D. S. A. (2016). A critical exploration of 'access' in qualitative international business field research: towards a concept of socio-cultural and multidimensional research practice. Qualitative Research in Organizations and Management: An International Journal, 11(2), 110-26.

Frenkel, M., Lyan, I., \& Drori, G. S. (2015). Reproducing self and the other: the role of cross-cultural management discourse and training in shaping Israeli-Korean collaborations. In N. Holden, S. Michailova \& S. Tietze (Eds.), Routledge companion to cross-cultural management (pp. 399-408). Oxford/New York: Routledge.

Guttormsen, D. S. A. (2010). International and intercultural experiences of expatriates in Hong Kong: an ethnography. MPhil thesis, Leeds University Business School.

Guttormsen, D. S. A. (2014). Constructing 'China': culture and U.S. think tank narratives - a Bourdieusian investigation. PhD thesis, University of Warwick.

Guttormsen, D. S. A. (2015). Looking forward by looking back: a self/other perspective on intercultural expatriate research. In N. Holden, S. Michailova \& S. Tietze (Eds.), Routledge companion to cross-cultural management (pp. 344-54). Oxford/New York: Routledge.

Guttormsen, D. S. A., Francesco, A., \& Chapman, M. (2018). Revisiting the expatriate failure concept: a qualitative study of Scandinavian expatriates in Hong Kong. Scandinavian Journal of Management, 34(2), 117-28.

Guttormsen, D. S. A., \& Lauring, J. (2018). Fringe voices in cross-cultural management research: silenced and neglected? International Studies of Management \& Organization, 48(3), 239-46.

Hammersley, M., \& Atkinson, P. (1995). Ethnography: principles in practice (2nd ed.). London: Routledge.

Harzing, A.-W., Reiche, B. S., \& Pudelko, M. (2013). Challenges in international survey research: a review with illustrations and suggested solutions for best practice. European Journal of International Management, 7(1), 112-34.

Hofstede, G. (1993). Cultural constraints in management theories. Academy of Management Executive, 7(1), 81-94.

Holmes, P. (2015). Intercultural encounters as socially constructed experiences: which concepts? Which pedagogies? In N. Holden, S. Michailova \& S. Tietze (Eds.), Routledge companion to cross-cultural management (pp. 237-47). Oxford/New York: Routledge. 
Jonasson, C., Lauring, J., \& Guttormsen, D. S. A. (2018). Inclusive management in international organizations: how does it affect local and expatriate academics? Personnel Review, 47(2), 458-73.

Jonsen, K., Butler, C. L., \& Mäkelä, K. et al. (2013). Processes of international collaboration in management research. Journal of Management Inquiry, 22(4), 394-413.

Keesing, R. M., \& Strathern, A. J. (1998). Cultural anthropology: a contemporary perspective (3rd ed.). Belmont, CA: Thomson.

Klitmøller, A., \& Lauring, J. (2013). When global virtual teams share knowledge: media richness, cultural difference and language commonality. Journal of World Business, 48(3), 398-406.

Klitmøller, A., Lauring, J., \& Bjerregaard, T. (2015). Researching supra- and sub-national contexts: multi-sited and extended ethnographic methodologies for language research. In N. Holden, S. Michailova \& S. Tietze (Eds.), Routledge companion to cross-cultural management (pp. 95-102). Oxford/New York: Routledge.

Lauring, J. (2007). Language and ethnicity in international management. Corporate Communications: An International Journal, 12(3), 255-66.

Lauring, J. (2008). Rethinking social identity theory in international encounters. International Journal of Cross Cultural Management, 8(3), 343-61.

Lauring, J., \& Guttormsen, D. S. A. (2010). Challenges of ethnicity in organizational interaction: the role of language use in expatriate management. In J. K. Crennan (Ed.), Race and ethnicity: cultural roles, spiritual practices, and social challenges (pp. 137-59). New York: Nova Science Publishers Inc.

Lauring, J., Guttormsen, D. S. A., \& McNulty, Y. (2019). Adult third culture kids: adjustment and personal development. Cross Cultural \& Strategic Management, 26(3), 387-400.

Lauring, J., \& Jonasson, C. (2018). Can leadership compensate for deficient inclusiveness in global virtual teams? Human Resource Management Journal, 28(3), 392-409.

Lauring, J., \& Klitmøller, A. (2015). Corporate language-based communication avoidance in MNCs: a multi-sited ethnography approach. Journal of World Business, 50(1), 46-55.

Lauring, J., \& Selmer, J. (2009). Expatriate compound living: an ethnographic field study. International Journal of Human Resource Management, 20(7), 1451-67.

Lauring, J., \& Selmer, J. (2010). The supportive expatriate spouse: an ethnographic study of spouse involvement in expatriate careers. International Business Review, 19(1), 59-69.

Linstead, S. (1997). The social anthropology of management. British Journal of Management, 8(1), 85-98.

Lynn, L. H. (2006). US research on Asian business: a flawed model. Asian Business and Management, 5, 37-51.

Malinowski, B. (1967). A diary in the strictest sense of the term. Stanford, CA: Stanford University Press.

Michailova, S., Piekkari, R. \& Plakoyiannaki, E. et al. (2014). Breaking the silence about exiting fieldwork: a relational approach and its implications for theorizing. Academy of Management Review, 39(2), 138-61.

Moore, F. (2011). Holistic ethnography: studying the impact of multiple national identities on post-acquisition organizations. Journal of International Business Studies, 42(5), 654-71.

Peng, M. W. (2004). Identifying the big question in international business research. Journal of International Business Studies, 35(2), 99-108. 
Pole, C., \& Hillyard, S. (2016). Finding the field. In C. Pole \& S. Hillyard (pp. 19-34), Doing fieldwork. London: SAGE.

Primecz, H., Romani, L. \& Sackmann, S. (Eds.) (2011). Cross-cultural management in practice: culture and negotiated meanings. Cheltenham, UK and Northampton, MA, USA: Edward Elgar Publishing.

Rosen, M. (1991). Coming to terms with the field: understanding and doing organizational ethnography. Journal of Management Studies, 28(1), 1-24.

Simon, H. (1991). Models of my life. New York: Basic Books.

Stoermer, S., Lauring, J. \& Selmer, J. (2020). Job characteristics and perceived cultural novelty: exploring the consequences for expatriate academics' job satisfaction. International Journal of Human Resource Management, 1-27 [online only]. Retrieved from https://www.tandfonline.com/doi/full/10.1080/09585192.2019 .1704824

Wacquant, L. (2004). Following Pierre Bourdieu into the field. Ethnography, 5(4), 387-414.

Wacquant, L. J. D., \& Bourdieu, P. (1992). An invitation to reflexive sociology. Chicago, IL: Chicago: University Press.

Welch, C., Marschan-Piekkari, R., Penttinen, H. \& Tahvanainen, M. (2002). Interviewing elites in international organizations: a balancing act for the researcher. International Business Review, 11(5), 611-28.

Welch, C., \& Piekkari, R. (2006). Crossing language boundaries: qualitative interviewing in international business. Management International Review, 46(4), 417-37.

Zhang, L. E., \& Guttormsen, D. S. A. (2016). Multiculturality as a key methodological challenge during in-depth interviewing in international business research. Cross Cultural \& Strategic Management, 23(2), 232-56. 